\title{
Integrating Joint Implementation Projects for Energy Efficiency on the Built Environment with White Certificates in The Netherlands
}

\author{
V. Oikonomou $\cdot$ W. van der Gaast
}

Received: 27 June 2006/ Accepted: 19 January 2007 / Published online: 13 February 2007

(C) Springer Science+Business Media, B.V. 2007

\begin{abstract}
In this paper we analyze policy interactions between two innovative climate and energy policy instruments, namely White Certificates (WhC) and Joint Implementation (JI) that target at energy efficiency improvement and reductions of Greenhouse Gas (GHG) emissions. We have selected The Netherlands and Bulgaria as a case study given that the former has a cumulated experience in energy efficiency policies and the latter for a growing potential in JI projects as a host country. Based on a method of analyzing policy interactions, we demonstrate how a possible design of such a scheme can take place and how it should function. A couple of parameters that deserve attention are a baseline definition and a conversion rate for credits. Our basic finding is that an integrated scheme is complementary and can assist substantially in achieving Dutch national United Nations Framework Convention on Climate Change (UNFCCC) Kyoto Protocol targets. Dutch electricity and gas suppliers (parties that receive energy efficiency obligations) can implement energy efficiency projects domestically and in other countries, hence reducing total abatement costs. Furthermore, such a scheme can stimulate further energy efficiency actions from other stakeholders participating in energy markets. Based on an ex-ante assessment, a carefully designed hybrid WhC and JI scheme appears to be effective in terms of targets, efficient, generating positive impacts on markets and society, while uncertain in stimulating innovation.
\end{abstract}

Keywords Joint implementation - White Certificates - Policy interaction · Energy efficiency $\cdot$ Built environment

V. Oikonomou ( $\square)$

SOM, University of Groningen, PO Box 800, 9700 AV, Groningen, The Netherlands e-mail: v.oikonomou@rug.nl

W. van der Gaast

Foundation Joint Implementation Network, Meerkoetlaan 30-a, 9765 TD Paterswolde The Netherlands 


\section{Introduction}

White Certificates (WhC), named also Energy Efficiency Titles, and is a new policy instrument implemented in some European Union (EU) countries. Its basic idea is that specific energy saving targets set for energy suppliers or distributors must be fulfilled by implementing energy efficiency measures towards their clients within a specific time frame. Such fulfillment is acknowledged by means of (White) certificates. Energy suppliers or distributors that save more energy than their targets can sell these surplus energy efficiency equivalents in the form of WhC to suppliers/ distributors that cannot fulfill their targets. Thus far, WhC systems have been implemented in the United Kingdom (UK), Italy, and France, albeit with different design characteristics and ambition levels. Since WhC is a rather new policy instrument, it has received relatively little attention in the literature, especially when compared to other policy instruments such as emissions trading, taxes, subsidies, and other certificate mechanisms. An extensive literature for $\mathrm{WhC}$ can be found in: (Bertoldi and Rezessy 2006; Bertoldi et al. 2005; EU SAVE "White and Green" project; EuroWhiteCert project; Farinelli et al. 2005; Guardiola et al. 2004; International Energy Agency 2006; Mundaca and Santi 2004; Oikonomou et al. 2007).

The concept of Joint Implementation (JI) has been at the center of climate policy making since its inclusion in the United Nations Framework Convention on Climate Change (UNFCCC) in 1992. The basic idea of JI is that industrialized countries can achieve their greenhouse gas (GHG) emission reduction commitments partly via emission reduction projects on the territory of other countries where marginal abatement costs are relatively low. The fact that GHGs mix evenly in the atmosphere implies that changing the location of abatement action does not affect its effectiveness. The JI concept has been fully included in the UNFCCC Kyoto Protocol through the adoption of two project-based mechanisms: the Clean Development Mechanism (CDM), which arranges project co-operation between industrialized countries and developing countries; and Joint Implementation among industrialized countries (i.e. countries with quantified commitments under the Protocol). The latter mechanism will be focused on in this paper.

Several industrialized countries and some multilateral organizations have established investment programs for JI projects: e.g., The Netherlands, Canada, Germany, Finland, Japan, the World Bank, and the European Bank for Reconstruction and Development. This has resulted in a pipeline, which contains almost $145 \mathrm{JI}$ projects (as per December 2006), i.e. projects that are in the process of validation of the project plan or that have been implemented. Limiting the geographical boundary to industrialized countries implies that in practice most projects are carried out in Central and Eastern Europe (including the Russian Federation) where marginal abatement costs are relatively low.

JI however faces considerable 'competition' from other policy measures. For instance, several formerly potential JI investment opportunities in the new Member States (those who entered the EU in May 2004) are now covered by the EU carbon dioxide $\left(\mathrm{CO}_{2}\right)$ emissions trading system (ETS), which has been operational since 2005. In order to avoid double counting, ETS-based emission reductions cannot be accounting for under JI. In addition, before their EU accession, new Member States had to incorporate the energy and environment standards of the EU Acquis Communautaire, which required an update of several installations and consequently 
the reduction of GHG emissions which otherwise could have been carried out under JI. Therefore, the EU accession has strongly reduced the JI potential in the new Member States, especially for energy intensive industrial and energy producing sectors.

The Netherlands has been a frontrunner in innovative energy policies and market mechanisms for climate change policy. Furthermore, it has been quite actively involved in various energy efficiency policies. The actual annual energy efficiency improvement rate is $1 \%$ ( $0.3 \%$ due to policy), while it should be $1.3 \%$ (as from 2008 ) and 1.5\% from 2012 (MinEZ 2005; Schneider 2005). Finally, The Netherlands has to take into account the EU Directive (EC 2006a) on the promotion of efficiency in energy end-use and energy services which suggests a non-binding $9 \%$ energy efficiency improvement spread over 9 years. Finally, the EU Action Plan for energy efficiency sets much higher targets at the level of $20 \%$ energy efficiency improvement by 2020, almost 390 Mtoe (million tonnes of oil equivalent) saved, given the existing potentials for such actions (EC 2006b). In order to close the gap between achieved and required efficiency improvements new policy instruments are considered by the Government. Among these is a domestic WhC scheme, which is currently under discussion although no official scheme exists. In the meantime, stakeholders have begun to exchange views and general ideas, including the set up of a WhC scheme, its implications for participants, and eventual effectiveness.

For The Netherlands JI (together with the CDM) is a key policy instrument for reaching the Dutch target under the Kyoto Protocol of an emission reduction of $6 \%$ below 1990 levels by 2008-2012. This target corresponds with a required reduction in terms of $\mathrm{CO}_{2}$-equivalent of approximately 200 Mtonnes (million tonnes) in total during this five-year period. To reach this target, The Netherlands Government decided in 1999 that 100 Mtonnes will be purchased from abroad through JI and CDM projects. One-third of this amount (33 Mtonnes) will be generated through JI projects.

As mentioned above, policy instruments could 'compete' with each other and reduce each other's effectiveness, but could also mutually enforce their effectiveness if combined well. The interaction of policies, or their compatibility, is therefore an important aspect to look at in the policy design stage. The issue of policy interactions between WhC and other climate policy market mechanisms has been dealt with in a few studies (Bertoldi et al. 2005; EU SAVE "White and Green" project (http:// www.iiiee.lu.se/whiteandgreen); EuroWhiteCert project (http://www.eurowhitecert.org); Farinelli et al. 2005). Besides Oikonomou et al. (2007) and Schneider et al. (2005), no specific case studies for The Netherlands on WhC are available.

$\mathrm{JI}$, on the other hand, has been widely studied, especially with respect to its compatibility with other policy measures such as ETS and environmental standards. As mentioned above, it has generally been concluded that JI's potential has decreased due to the accession of 10 new Member States in May 2004 (Van der Gaast 2002). However, little attention has been paid to how JI's potential could be enhanced if it were combined with other policy mechanisms, which envisage trading a product (credit, certificate) that is directly or indirectly comparable to the reduction of a ton $\mathrm{CO}_{2}$-equivalent (such as energy efficiency). Given that WhC and JI share the same policy targets (energy efficiency improvements and GHG emission reduction), JI credits might be convertible into White Certificates. This would, in principle, provide a scope for WhC scheme participants to purchase WhC in other 
countries where the marginal costs of energy efficiency improvements are relatively low.

In the literature there is an important gap in terms of the exploration of interactions and combinations of policy instruments that have the same objectives but that use fundamentally different methodologies to calculate the eventual achievements. The main objective of this paper is to analyze potential policy interactions between WhC and JI in the Dutch context. The Netherlands has been selected as case study investing country since it is experienced in JI projects and has already implemented many energy efficiency improvement policies. Bulgaria has been chosen as a case study host country for a number of reasons. First, it has acceded the EU as per 1 January 2007, which implies that it has incorporated EU standards in its domestic legislation and daily practice (with some transition arrangements to incorporate standards at a later date). Second, Bulgaria is likely to join the second phase of the EU ETS in 2008. Third, despite that the EU accession has basically reduced its JI potential, Bulgaria has expressed a strong interest in JI co-operation, especially in the fields of renewable energy, co-generation, transport, waste management, and built environment. Of these fields, built environment is particularly interesting for simulating policy interaction between JI projects (in built environment improvement) and Dutch WhC objectives. It enables an analysis of how feasible a Dutch hybrid scheme (WhC with optional JI) could become. Of course, this analysis could also be applied to other sectors with energy efficiency improvement potential (e.g. transport, industry, co-generation) but we limit ourselves in this paper to a 'simpler' version of a WhC/JI scheme.

In section 2 we explain our basic method used for analyzing interactions between WhC and JI and for exploring options for integrated policies. Through this method we identify types of possible interactions and present a detailed outline of all design characteristics of these policies together with a couple of options for integrating them in the Dutch context. In the same section we focus in detail on two parameters that seem to hamper harmonization of JI and WhC, namely how to set baselines/ benchmarks for the calculation of achievements of JI and WhC, and how to convert JI credits into WhC. Furthermore, in section 3 we depict the functioning of a hybrid scheme in The Netherlands, where electricity and gas suppliers can opt-in for JI projects in Bulgaria as a host country. We portray how a combined scheme of JI and WhC can enhance energy efficiency improvement and cost-effectiveness of these instruments. Finally, in section 4 we assess with the help of a number of criteria our proposed hybrid scheme and provide some conclusions and policy recommendations.

\section{Links between White Certificates and JI}

In this paper we use a method for analyzing policy interaction developed by Oikonomou and Jepma (2006). This method is purely qualitative and consists of three steps: (a) identification of desired interactions, (b) in-depth analysis of design characteristics of the policies to be integrated by considering them individually and in a combined setting, and (c) assessment of interaction based on specific criteria, with degrees of uncertainty and weighting factors (revealing trade-offs and preferences of policymakers) for each specific criterion. With this method we analyze 
possible interactions and options for combining JI projects in the built environment (based on the set up of the Dutch Emissions Reduction Units Procurement Tender (ERUPT) program) with a hypothetical Dutch WhC scheme. A basic advantage of this method is that it can reveal all possible complementarities and overlaps of these policies in detail, identify problems, and offer solutions in an integrated scheme for energy efficiency improvement. The entire method consists of many parameters, but we use only those that are most relevant for the JI-WhC interaction, due to the fact that there is yet no Dutch WhC scheme and many design characteristics are unknown. We also confine ourselves to a small number of assessment criteria do not use the possibility of setting specific weighting parameters, since ex-post knowledge of these instruments is rather limited and uncertainties are high.

In this section we explore the feasibility for The Netherlands of a scheme where electricity and gas suppliers, under an energy efficiency obligation, implement JI projects aiming at energy efficiency in buildings in another country (e.g. Bulgaria) and convert the $\mathrm{JI} \mathrm{CO}_{2}$ credits into WhC. First, we define possible interactions between $\mathrm{JI}$ and $\mathrm{WhC}$ schemes and generate our desired dual scheme. As a second step, we analyze all design characteristics of JI and WhC both as stand-alone instruments and integrated in a scheme. Finally, we focus on two accounting issues that are crucial for the integration of JI and WhC: the methods to calculate the GHG emission reductions from energy efficiency JI projects (in particular the setting of the GHG baseline scenario) and the rate for converting JI $\mathrm{CO}_{2}$-equivalent credits into WhC.

\section{Types of interactions between $\mathrm{JI}$ and WhC}

As an initial step in our analysis we list possible interactions (explained in detail by Oikonomou and Jepma (2006)) between WhC and JI, according to their scope (level of governance and policy context), their interacting function (trading, time sequencing), and their degree of integration (fungibility or stand-alone measures). We distinguish interactions according to: their regional impact (national or international), the objectives addressed (same or different policy context), timing of start and end of each policy (sequencing), and conversion of their trading commodities (separation, one way and double fungibility). The outcome of such categorization depends on policymakers' objectives when implementing different policies simultaneously. In Table 1 we present different interactions between $\mathrm{WhC}$ and $\mathrm{JI}$ and a

Table 1 Typology of interactions

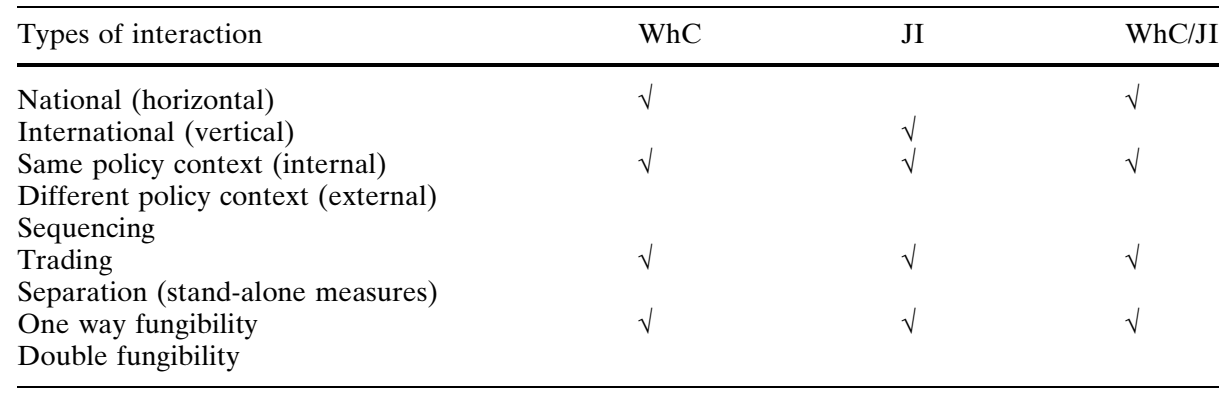


proposed integrated scheme, which assist us in designing the second step of our method.

We can deduce from Table 1 that an integrated JI/WhC scheme for energy efficiency projects in the built environment can be complementary, provided that JI credits are aimed at fungibility with WhC within The Netherlands. Furthermore, both instruments refer to the same policy context, which facilitates a common design in terms of target setting. Both WhC and JI can be used as trading mechanisms, meaning that JI Emissions Reduction Units (ERUs) can be converted to WhC under a pre-specified conversion rate. Given the objective of this paper is to explore how JI projects could assist in achieving energy efficiency targets set in The Netherlands, we only look at how ERUs could become WhC, not the other way around.

Areas of policy interaction between $\mathrm{WhC}$ and JI

In this section we assess the design characteristics of $\mathrm{WhC}$ and $\mathrm{JI}$ and present an optional integrated scheme based on these characteristics. Some design parameters of a Dutch WhC scheme are fictional, since no official scheme exists and only preliminary discussions have taken place so far. Table 2 presents these characteristics for WhC and JI individually and two options of integrating these instruments, based on our preference of one-way fungibility as explained before. We take into account only the first option for an integrating scheme (the second is purely demonstrative). A detailed analysis of these parameters can be found in Oikonomou and Jepma (2006).

\section{Design characteristics of a potential hybrid scheme}

A general outcome from Table 2 is that a voluntarily integrated scheme of $\mathrm{JI}$ and WhC (maintaining the obligatory element of WhC) can be complementary and enhance energy efficiency improvement at a national and international level: reducing $\mathrm{CO}_{2}$ and primary energy use support both energy and environmental goals. More specifically, in terms of objectives, a hybrid scheme can facilitate installations under a WhC scheme to achieve their obligations through implementing more costeffective energy efficiency projects in another country.

Within the scope of the scheme, the parties with energy efficiency improvement commitments are electricity and gas suppliers and the energy efficiency projects are implemented in the non-energy intensive (mainly households and tertiary) sectors.

Eligible parties without obligations can be Energy Service Companies (ESCO's), installators and building companies that can invest in energy efficiency projects abroad (or domestically) in collaboration with local building companies and receive hence ERUs (similar process to electricity and gas suppliers).

Market parties eligible to trade WhC could be entities that generate ERUs and WhC through their actions. Alternatively, all companies could be eligible for trading, which would increase market liquidity, but which could also jeopardize actual energy efficiency actions when low-price ERUs are included in the scheme which do not originate from energy efficiency actions. In this hybrid scheme a niche in the JI market is created, where prices could be higher than the overall carbon market price; after all energy suppliers can only purchase energy efficiency based credits and compare their price with their domestic energy efficiency projects' costs instead of 


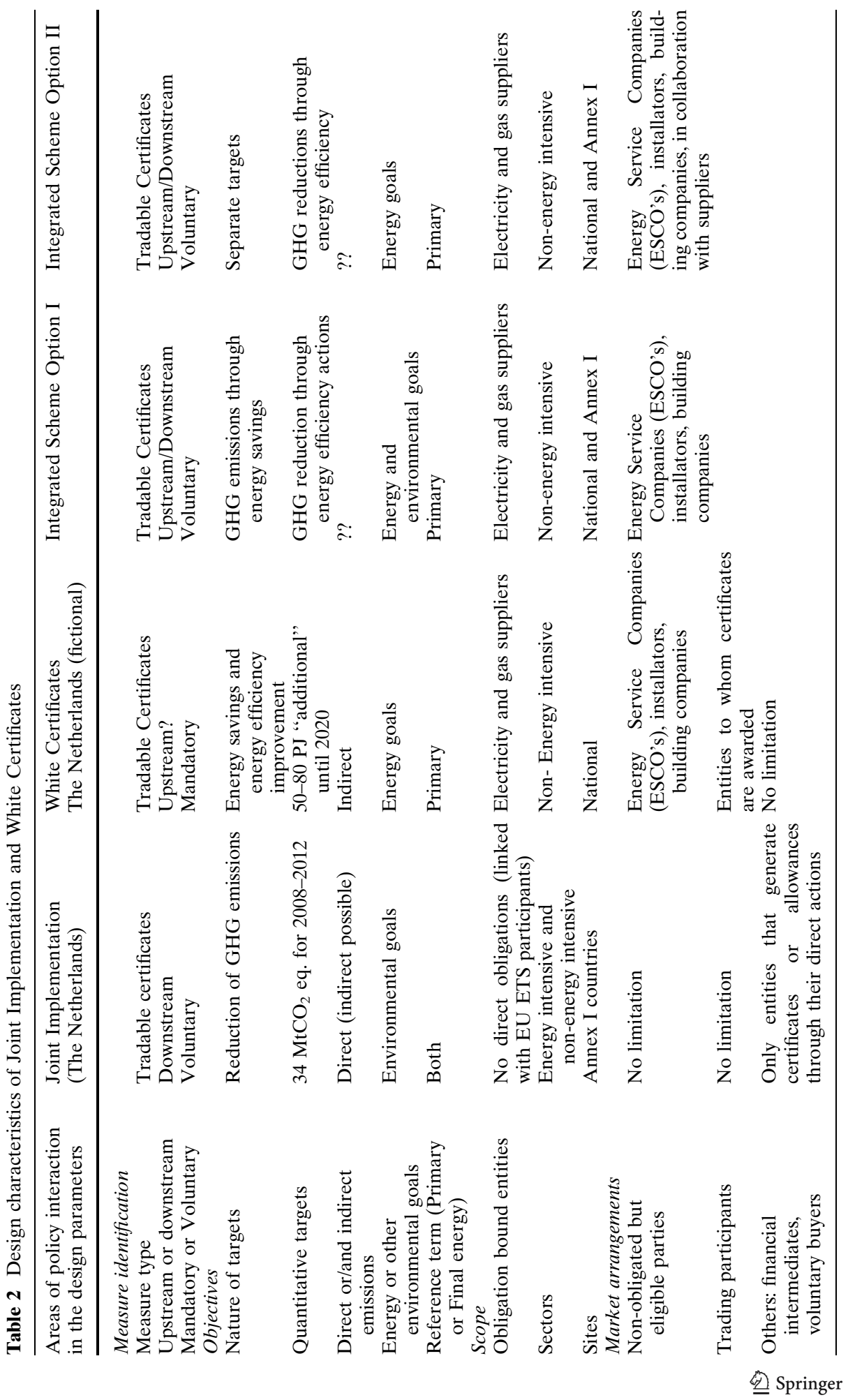




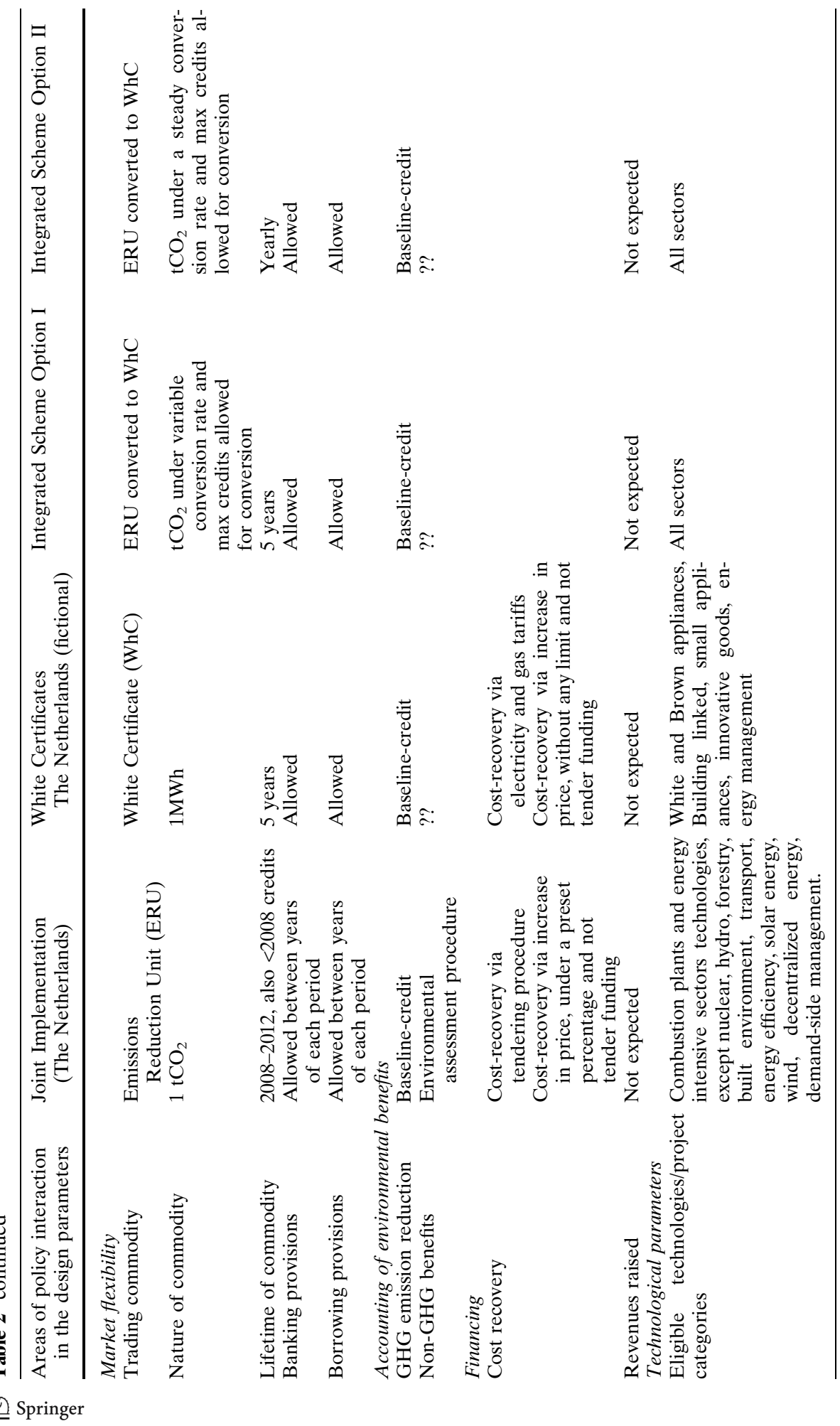




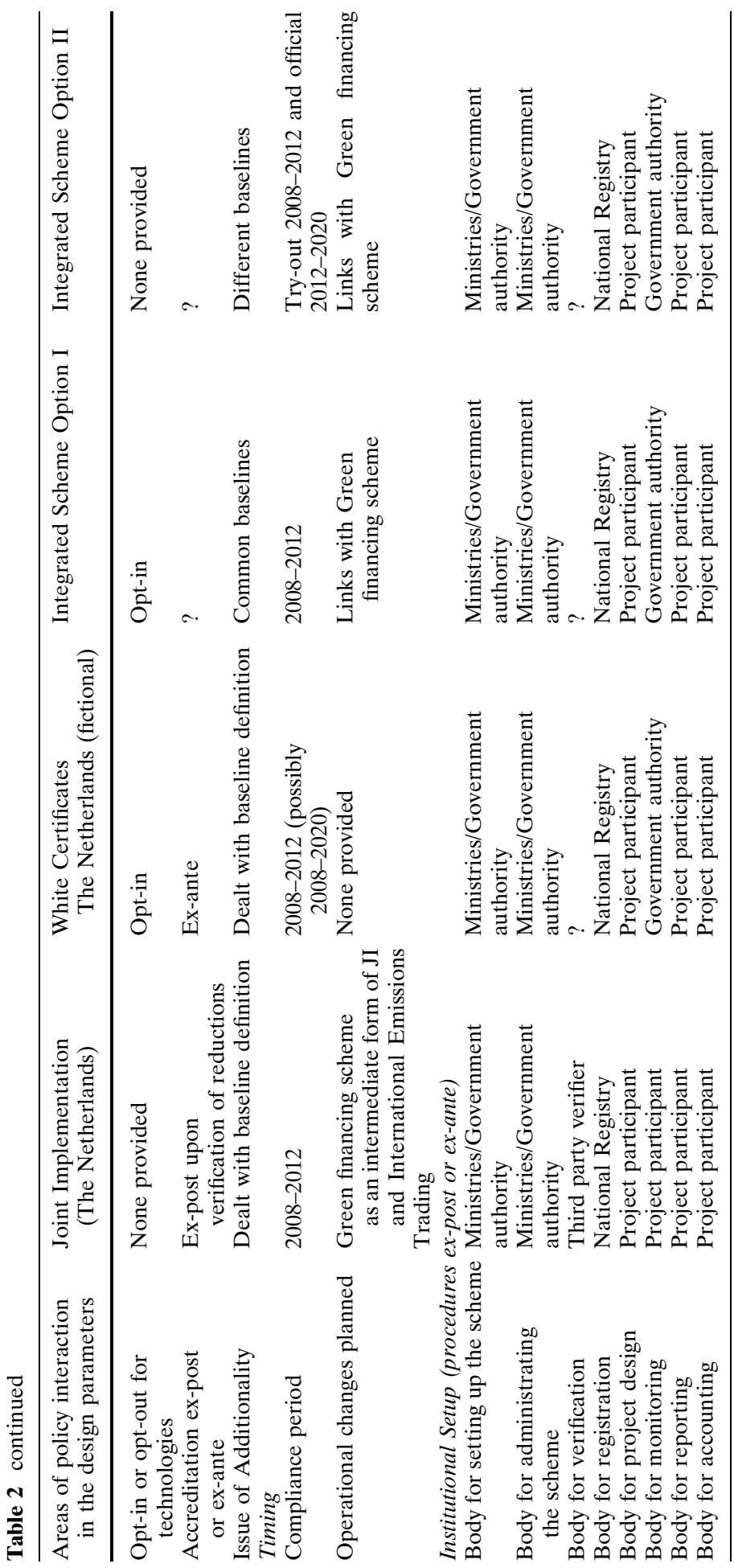


the price of other ERUs. We exclude nevertheless consumers, since they are not considered as a trading party under a Dutch WhC scheme (Schneider 2005).

The trading commodity (WhC) can be expressed in MWh (MegaWatt hours) saved per ton $\mathrm{CO}_{2}$ reduced, based on a steady or variable conversion rate (see for further details Section 2.4). Energy efficiency projects can be financed through an increase in electricity and gas tariffs and from selling WhC. In order to reduce windfall profits, electricity and gas suppliers that opt for JI projects should receive only a percentage (or not at all) of governmental subsidies (from JI tenders) as project financing. Furthermore, a prerequisite for eligibility of converting ERUs into WhC if they originate only from pre-approved activities (approved by the governments of Bulgaria and Netherlands and designed in accordance with modalities and procedures under the Kyoto Protocol) in the field of energy efficiency in the built environment. In terms of timing, a try out phase of the integrated scheme could start during the first commitment period of the Kyoto Protocol (i.e. 2008-2012) and an official functioning can be planned for 2012-2020. Finally, no bottlenecks appear in governing and monitoring bodies, since the same authorities undertake both WhC and JI.

\section{Baseline definition}

Emission reductions achieved by JI projects are calculated by taking the difference between the GHG emissions that would have taken place in the absence of the project (business-as-usual) and the actual GHG emissions under the project. The latter emissions can be relatively easily monitored as these actually take place. The business-as-usual emissions, though, are much more difficult to estimate as these are replaced by the project. Therefore, such a reference scenario or baseline is largely hypothetical and difficult to monitor.

GHG emission baselines can at best be based on a set of assumptions about the future development of project-related variables, such as: host country's economic growth perspective, demographic development, relevant government policies, etc. Given the uncertainties that surround the estimation of such variables, there could be a risk that $\mathrm{JI}$ partners deliberately overstate baseline emissions in order to claim more GHG emission reduction credits from JI projects. This would reduce the environmental integrity of JI as the claimed emission reductions are not actually realized, while they are still sold to a foreign JI investor who uses them as compensation for domestic GHG emission increases, or in the case of WhC, less energy efficiency improvement.

For the built environment, baseline determination faces an additional complication. Determining a baseline for each building modernized by a JI project could, due to the relatively small scale of the emission reductions, be rather costly. Instead, it could be an option to develop baselines that could be used for a multitude of projects so that one baseline would need to be determined for a number of buildings. This standardized, multi-project baseline, the costs of a baseline could be spread across a larger range of projects (i.e. buildings). Moreover, standardization of baseline procedures increases transparency of GHG accounting procedures: for each project the same calculations are used which could enhance the fungibility of JI credits in a WhC scheme. Finally, it reduces the opportunities for individual project developers 
to overstate baseline emissions; it is only needed to check whether the standard baseline reasonably describes the business-as-usual circumstances.

However, the determination of a standardized/multi-project baseline in itself may require more time and data than one project-specific baseline, as it generally requires a macro and/or sector analysis. When applying multi-project baselines in the JI Track-I context the issue remains how such baselines are to be financed. ${ }^{1}$ Host countries may argue that they lack funding to carry out multi-project baseline studies, whereas investor countries may be concerned about free-rider effects that may occur if one of them pays for a baseline study which all other investors can subsequently use for free (Van der Gaast 2005).

Standardizing baselines for the built environment is generally considered difficult, as each building is unique in terms of a combination of building material used, design, use of the building, maintenance, etc. A first step in the standardization process could be the assumption that buildings are generally built to regulations and no further. Second, an assumption must be made on the extent to which compliance with these regulations has taken place; this may differ from country to country. Third, governments may (have to) formulate improvements in the built environment, either through domestic policies or through EU pre-accession processes.

Moreover, in the built environment a distinction can be made between residential and non-residential buildings. For example, a JI project could aim at improving energy performance of a particular type of houses, e.g. mass residential buildings in an Eastern European country from 1970s to 1980s with prefabricated walls, floors, roofs, bad thermal insulation, and the owner being the occupant. A possible multiproject baseline could be derived from the energy performance of a default site, e.g. the Ovtcha Kupel district in Sofia.

Meanwhile, the largest scope for multi-project baselines seems to exist in the nondomestic sub-sector, e.g. offices, schools/universities, hospitals, hotels, warehouses, and libraries (Begg et al. 2002). Begg et al. (2002) demonstrate an example for the UK Department of Trade and Industry (DTI) in 2002 which aimed at exploring procedures for generating GHG credits from among sectors the built environment for trade within the UK Emissions Trading Scheme. Examples of parameters to be taken into consideration when determining a baseline for built environment projects include:

- Project type-Does the project construct a new building thereby replacing an existing one or an otherwise newly construct buildings. In the first case the multiproject baseline is generally based on the performance of the old building; in the second case, the baseline is the performance of the type of new building that would otherwise have been built. Finally, a project could aim at refurbishing an existing building, the baseline of which would again be the energy performance of the building before the project, adjusted for planned improvements due to government regulations.

- Elemental or whole-building method-A project could aim at improving a particular building element, e.g. heating, equipment, cooling, lightning, and

\footnotetext{
${ }^{1}$ JI Track-I refers to the simplified accounting procedures included in the Marrakech Accords (2001) which Annex I Parties may apply if they meet minimum system requirements in terms of GHG inventories, National Communications, etc. The main simplification under Track-I is that Parties may bilaterally agree on JI projects and the GHG accounting procedures, without validation and verification involvement of accredited third party entities.
} 
ventilation, and a multi-project baseline could describe the present and expected energy performance of each element. For example, under the CDM, a project has been proposed which aims at improving the room air conditioning standards in buildings in Ghana. The baseline for this sector-policy project is the emissions level of present air conditioning practices in the country. A whole-building multiproject baseline determines a fixed emission factor per e.g. $\mathrm{m}^{2}$ for schools, hospitals, office buildings, etc.

- Owner/occupier/tenant-it makes quite a difference whether the owner of a building is also the occupier or manager, or not. Simply put, when the owner must also pay the energy bill, he/she may have a stronger incentive to carry out energy saving measures than in case the energy bills go to the occupier/tenants.

In the case of Bulgaria, possible data inputs for a baseline are (Van der Gaast, 2005):

- the present energy performance of non-domestic buildings in Bulgaria.

- the 1992/3 Regulation no.1 in Bulgaria, which sets minimum standards for heat insulation efficiency, but which are generally below the EU standards.

- the 1995 New Regulation Pr EN 12086/1995, which, however, faces enforcement difficulties due to lack of funding.

- the 2002 EU Directive on Energy Performance of Buildings

Based on Begg et al. (2002), a decision tree for a baseline selection in the built environment can include is divided between new buildings and refurbishment. For both new buildings and refurbishments, parameters taken into account are the building envelope, services, equipment, and energy supply. Furthermore, the baseline is defined according to the tenancy structure, which can consist of: (a) Owner and Occupier, (b) Owner and Tenant, (c) Owner, Management Company and Tenant, and (d) Owner, Management Company and Multiple Tenancy.

Given the complexity of the accounting (including monitoring) of GHG emission reductions from built environment projects it has often been argued that sectorbased projects with multi-project baselines are more suitable than building-specific projects with project-specific baselines (Bossi and Ellis 2005).

In the case of a Dutch scheme for WhC, alternative options for the determination of a baseline have been proposed. Some harmonized methodologies depending on the nature of energy efficiency goods and projects can be used to enhance the scheme. To this cause, a basic division of energy efficiency actions in order to achieve simplicity has been discussed during the design phase where specific rules apply to each case. Measures are divided into: building linked ('hard' measures, e.g. insulation), efficient brown and white goods ('soft' measures, e.g. appliances), small measures (e.g. energy efficient lighting), behavioral measures (e.g. energy management systems), innovative and new goods, and leasing goods.

In line with the parameter choices shown for JI baseline definition above, in most cases, especially for goods (i.e. appliances), a deemed saving approach has been chosen similar to the Italian WhC scheme (International Energy Agency 2006). This approach is applied for projects where energy savings can be easily estimated and there is no further need for direct measurement. According to this method, the total amount of energy saved is calculated by multiplying the number of installed highefficiency appliances and devices with pre-set values for the energy savings per appliance/device. Gross savings can be converted to net savings through the use of a factor of free-riding effects and probably a second factor for the impacts of different 
delivery mechanisms. This kind of evaluation could be used for the replacement of incandescent lamps with compact fluorescent lamps (Oikonomou 2004). These savings are based on a realistic energy saving value, which is corrected for rebound effects, misuse, and effective life span of measures (Schneider 2005). Various methods for monitoring and calculating energy savings from energy efficiency projects are presented exhaustively in Boonekamp (2006).

For white, brown, and smaller energy efficient goods the additionality of emission reductions and energy efficiency improvements can be shown by certifying energy savings from introducing newer products using existing energy efficiency labels for appliances. These labels show that the products have a better energy efficiency performance than the ones with the highest market penetration. Savings for behavioral and innovative measures are calculated with an estimation of the previous method and corrected for erosion of end user's behavior and rebound effects. In order to facilitate procedures, for white, brown, and behavioral goods a minimum quantity installed eligible for certification is 500 items, which are demonstrated in the seller's receipt. For smaller goods, eligible for certification are minimum 10,000 items, which are registered, and the seller periodically reports new items purchased.

Concerning the building linked measures, another method has been proposed that associates energy savings with energy efficiency indexes according to the EU Directive on energy performance in buildings (EPBD) (EC 2002). This approach links an Energy Index (EI) which addresses Carbon Dioxide $\left(\mathrm{CO}_{2}\right)$ reduction using on building characteristics with generation of WhC for energy savings. The Energy Index originates from the already applied method of Energy Performance Advice (EPA). For more information see Joosen et al. (2004) and SENTERNOVEM (http://www.senternovem.nl). The energy index (EI) is a figure depicting energy use of a building under some standard conditions. A low value of the index signifies lower energy use. For hard measures, energy saving value of energy efficiency projects is calculated as EI before minus EI after the realization of these projects associated with the lifespan of savings upon these projects. The EI is corrected according to surface, type, and construction year of the building. The difference of an EI before and after the realization of savings $(\Delta \mathrm{EI})$ can generate WhC through different ways: by realizing a minimal $\Delta \mathrm{EI}$ of 0.1 or 0.15 , by realizing a minimum $\Delta \mathrm{EI}$ of 0.1 or 0.15 where a threshold of the average EI is achieved, or by realizing a minimum $\Delta \mathrm{EI}$ of 0.1 or 0.15 where an initial part of savings does not count for WhC since it is considered as autonomous (hence subtracting deadweight loss). An optional link of EI metering for a Dutch WhC scheme can be found in Poel (2005). For building linked measures, in order to reduce transaction and monitoring costs, a minimum of 50 buildings (or identical houses) are eligible for certification of WhC after demonstrating the required $\Delta \mathrm{EI}$.

Finally, as far as the integrated $\mathrm{WhC/JI}$ scheme is concerned, standardized baselines in a unified form for both instruments could be rather difficult to implement. As was shown above, different methodologies apply for energy savings under these instruments and an adaptation of a Dutch approach for WhC to a country that does not apply such laws could be rather time consuming. It must also be noted though that some new Member States, which could potentially act as JI host country in a WhC scheme, have transition arrangements with the EU on the implementation of some parts of the EU Acquis Communautaire. In some countries, the EPBD Directive may not yet have been incorporated in domestic law, so that the preAccession EPBD situation would serve as the basis for the baseline. Nonetheless, we 
acknowledge that for some countries (e.g. Bulgaria) that will need to adapt to the EPBD, similar methods might apply and therefore monitoring mechanisms for both instruments can be simplified. An ideal situation for the time being therefore can be that $\mathrm{WhC}$ and JI maintain their own baseline methodology and monitoring setting, thereby avoiding multiple conversions of energy savings.

\section{Conversion rate}

A second issue of utmost importance for the functioning of similar certificate policies is the definition of a conversion rate between credits from different policy instruments. In our hybrid scheme credits represent different physical units: $\mathrm{MWh}$ of primary energy for $\mathrm{WhC}$ and $\mathrm{CO}_{2}$-equivalent emissions for ERU's. Obviously, the chosen accounting method has implications for how to convert JI credits to WhC: from $\mathrm{CO}_{2}$ reduction to WhC or from $\mathrm{JI}$ energy efficiency to WhC energy efficiency. Given that the hybrid scheme has to maintain simplified procedures that can decrease administrative and transaction costs, a conversion of $\mathrm{CO}_{2}$-equivalent to $\mathrm{WhC}$ is a preferable option. To this cause, a preset conversion rate has to be defined from $\mathrm{CO}_{2}$-equivalent to $\mathrm{MWh}$ based on the efficiency in The Netherlands (1 $\left.\mathrm{ERU}=1 \mathrm{tCO}_{2} \approx 5,000 \mathrm{MWh}=5,000 \mathrm{WhC}\right)^{2}$. Energy suppliers can receive $\mathrm{WhC}$ based on this conversion factor.

Similar to the EU linking Directive on establishing a scheme for greenhouse gas emission allowance trading within the Community, in respect of the Kyoto Protocol's project mechanisms (EC 2004), only project operators that are under an energy efficiency improvement obligations are allowed to convert ERUs into WhC and trade them domestically. Furthermore, as mentioned above, under a steady conversion rate, only ERUs originating from energy efficiency actions should be accepted in the market. In order to prevent abuse, energy suppliers should demonstrate to the national registry that the ERUs are the result of an energy efficiency project. In this context, the International Transaction Log of the Kyoto Protocol, which tracks all Kyoto-based emission reduction credits through unique serial numbers, could play an important role; the serial number would reveal the origin of the ERUs. An alternative conversion option in case there is no pre-approved list of actions under JI eligible for WhC could be that this conversion rate changes with higher values for "pure" energy efficiency actions under JI and lower values for other JI projects. From an administrative point of view, we consider that a steady conversion rate, predetermined by The Netherlands, which translates savings from abroad to $\mathrm{CO}_{2}$-equivalent and then to domestic MWh saved, can substantially reduce administrative costs and facilitate the integrated scheme.

\section{Application and function of a hybrid scheme}

In this section we present and evaluate our proposed integrated scheme of JI and WhC for The Netherlands. Initially, we demonstrate the functioning of this scheme and all possible activities that key players need to undertake as specified by both policies. In a second step, based on some studies on the energy saving potential of

This conversion is approximated as $1 \mathrm{tCO}_{2}=0.018 \mathrm{PJ}=18 \mathrm{TJ} * 277.8(\mathrm{GWh}) \approx 5,000 \mathrm{MWh}$ (International Energy Agency 2003).

篮 Springer 
both countries, we estimate, both technically and financially, the maximum energy savings that can be achieved when both $\mathrm{JI}$ and $\mathrm{WhC}$ are implemented. Finally, we evaluate our results on the grounds of some criteria in order to unveil positive and negative implications.

Presently, as far as the new EU Members States (including Bulgaria and Romania) are concerned, the main potential for JI seems to be in those sectors that are not covered by the EU ETS and where energy performance improvements are feasible beyond the Acquis Communautaire levels. According to Van der Gaast (2005), in these countries the main JI potential is in renewable energy production, transport, built environment, waste management, and co-generation as far as not covered under the ETS.

Departing from the current situation on WhC and JI mechanisms, we demonstrate in Fig. 1 a hybrid scheme of WhC and JI: the WhC scheme has a national scope within The Netherlands and JI projects for energy efficiency improvement are subsidized by The Netherlands and implemented in Bulgaria. We consider JI projects under Track I due to the political status of Bulgaria and its participation in Annex I countries. Basic players are electricity and gas suppliers, ESCOs (including other market participants that can implement energy efficiency projects), end users in The Netherlands, and end users in Bulgaria (symbolized as Buildings). Institutional players are authorities in both countries and an independent entity for JI, while two trading platforms exist, one for ERUs and one for WhC.

Initially, Dutch authorities assign energy efficiency targets to electricity and gas suppliers. In order to comply with their targets, the latter face three options: implementing energy saving projects focused on domestic end-users, purchasing WhC, and implementing energy saving projects in Bulgaria. The eventual choice depends on marginal costs and timing of each option, since costs per specific technology differ in each country and credits may not be delivered at the same time (i.e.

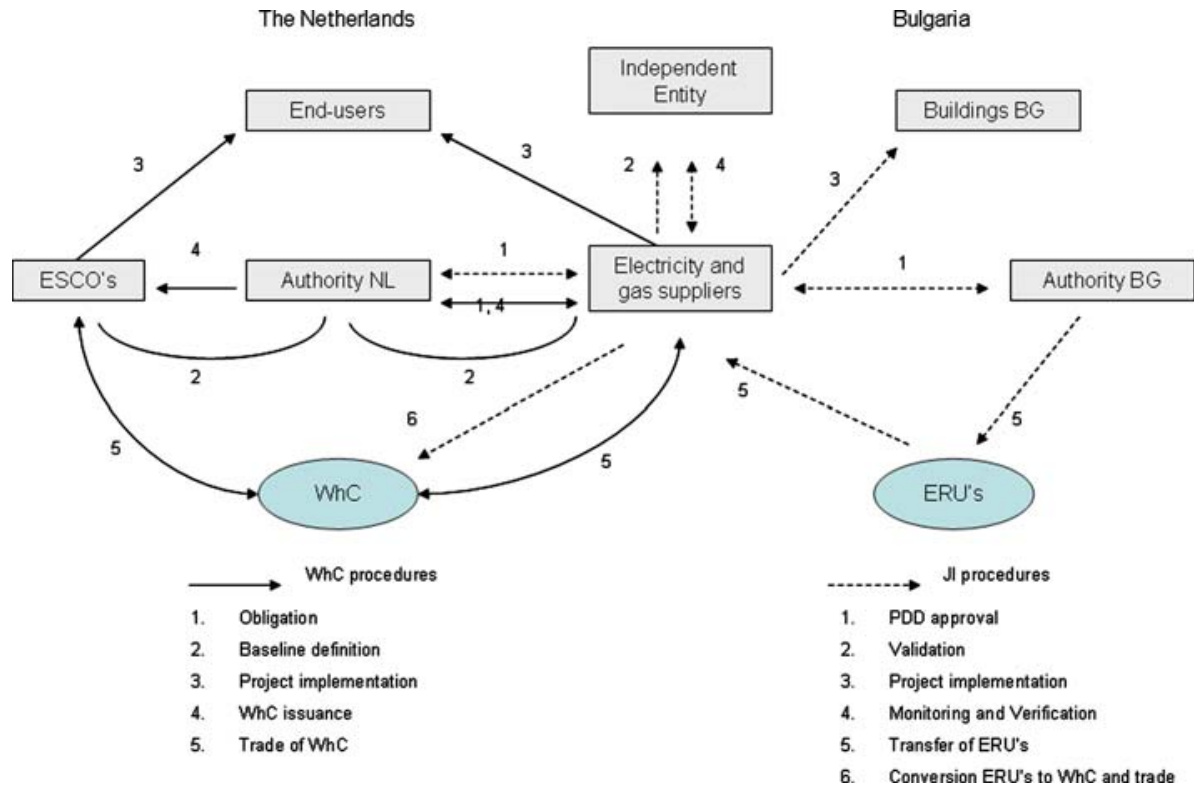

Fig. 1 Function of a hybrid scheme of WhC and JI 
ERUs could either be contracted through a forward contract with future delivery after realization of the emission reduction, or transferred on a spot-market basis when realized). We acknowledge that this scheme can be enhanced if distorted prices and unjustified subsidies in Bulgaria are eliminated and consumers start paying the full costs of their energy use. In this case demand for energy efficiency can slightly increase.

If suppliers opt for fulfilling their obligations through domestic actions (with Dutch end users), they present their envisaged energy savings from projects to the Dutch authorities and, if approved, they can implement the projects. Subsequently, they receive $\mathrm{WhC}$, which they can use for their compliance or can sell to other parties. If they cannot meet their target by the end of a specific period they receive sanctions (possibly in the form of fixed penalty) that function as a ceiling price of WhC (assuming that the system does not require paying a penalty and still make up for the deficit). ESCOs and other market participants can also implement energy saving projects, following the same procedure as suppliers, but with a main difference that they do not have commitments and would only participate on a voluntary basis; they would be able to sell their realized energy efficiency gains in the WhC market.

When electricity and gas suppliers opt for JI energy saving projects, they have to submit a Project Design Document for approval to Dutch and Bulgarian authorities (including validation of the project plan). This is a requirement of the Kyoto Protocol. When the project is approved, electricity and gas suppliers in collaboration with domestic or host country ESCOs and other market parties can proceed with project implementation. After an agreed period, an accredited independent entity monitors the actual emission reductions (or energy use improvement of the building) on the basis of which the Bulgarian authorities can issue ERUs to the partners. The total emissions reduced are subtracted from the Assigned Amount Units (AAU) of Bulgaria under the Kyoto Protocol and added to The Netherlands AAU. These extra AAU compensate for the energy efficiency improvement not taking place in The Netherlands as the project is carried out in Bulgaria. Electricity and gas suppliers can hence import ERU's and convert them up to a predefined percentage to WhC under a conversion rate.

Electricity and gas suppliers must demonstrate with this transaction that ERUs originate from a realized energy efficiency project in Bulgaria. After converting credits, suppliers can sell their surplus of WhC and finance partly their investments for energy efficiency, while exploiting incentives for further project implementation domestically. Furthermore, they can also avoid implementing energy efficiency investments since they acquire extra WhC (originating from JI projects) for the next period, provided that banking is allowed. We acknowledge that more complex procedures might in fact be required for the functioning of the whole scheme, but we present a rather simplified version where transaction and administrative costs can be kept relatively low.

\section{Outcomes of a hybrid scheme: energy, environment and economic benefits}

Potential for energy savings and emissions reduction with a hybrid scheme

The Netherlands has a $6 \%$ emission reduction commitment under the Kyoto Protocol (2008-2012) targets and aims at a 10\% reduction in post-Kyoto targets (2020). 
Table 3 Emission Reduction Units contracted from Emission Reduction Units Procurement Tender programs (expressed in $\mathrm{MtCO}_{2}$ equivalent)

\begin{tabular}{lllc}
\hline $\begin{array}{l}\text { JI project Financing for } \\
\text { The Netherlands }\end{array}$ & $\begin{array}{l}\text { Target } \\
\text { (from JI projects) }\end{array}$ & $\begin{array}{l}\text { Achieved amount } \\
\text { (contracted projects) }\end{array}$ & $\begin{array}{l}\text { Amount remaining } \\
\text { (to be contracted) }\end{array}$ \\
\hline ERUPT & 15 & 12.9 & 2.1 \\
PCF & 3 & 1.4 & 1.6 \\
EBRD & 6 & 0.3 & 5.7 \\
IBRD and IFC & 10 & 0 & 10 \\
Total & 34 & 14.6 & 19.4 \\
\hline
\end{tabular}

Note: Table data extracted for 1 January 2005. Currently, through ERUPT a total of $16.14 \mathrm{MtCO}_{2}$ equivalent have been contracted

Source: (CE 2005, p 4)

ERUPT: Emission Reduction Units Procurement Tender

PCF: Prototype Carbon Fund

EBRD: European Bank for Reconstruction and Development

IBRD: International Bank for Reconstruction and Development

IFC: International Finance Corporation

The Kyoto Protocol target sets 199.3 $\mathrm{Mt} \mathrm{CO}_{2}$-equivalent for the commitment period, from a $211.7 \mathrm{Mt} \mathrm{CO}_{2}$-equivalent of the base year, while in 2003 emissions in The Netherlands have reached 214.8 $\mathrm{Mt} \mathrm{CO}_{2}$-equivalent (Goldewijk et al. 2005). During 2008-2012, 33 million tonnes $\mathrm{CO}_{2}$-equivalent emission reductions are to be purchased from JI projects (see Section 1). Bulgaria plays a prominent role in the Dutch ERU procurement activities (CE 2005) Table 3.

Based on some preliminary studies for The Netherlands (Oikonomou et al. 2007; Schneider 2005), a WhC scheme for households can be cost-effective and reduce up to $80 \mathrm{PJ}$ primary energy in 2012, while for the period up to 2020 savings can reach a range of 180-240 PJ saved, which can be translated into 10.3-13.6 $\mathrm{Mt} \mathrm{CO}_{2}$. This amount can be achieved given that all cost-effective available energy efficiency measures can be installed and all technical and non-technical barriers for energy efficiency will be overcome. ${ }^{3}$ It should be noted that the total cumulative $\mathrm{CO}_{2}$ reduction (1995-2002) achieved from all the existing energy efficiency policy instruments in the built environment was $2.4 \mathrm{Mt} \mathrm{CO}_{2}$ (Joosen et al. 2004).

Given these figures and the proposed target of a WhC in The Netherlands it can be clearly demonstrated that in order to avoid market pressure to suppliers, some degree of flexibility can be provided through allowing them to implement energy efficiency projects in Bulgaria and utilizing them for their domestic obligations.

\section{Multi-criteria assessment of hybrid JI-WhC scheme}

A final step of our method consists of assessing, mainly on an ex-ante basis, the examined hybrid scheme of WhC with JI. Our evaluation is based on a list of criteria and subcriteria that refer to the triptych: energy, environment, and society. A detailed list with explanations of these criteria can be found in Oikonomou and Jepma (2006). More specifically, the criteria we employ are determined as: (a) Effectiveness

\footnotetext{
${ }^{3}$ This figure nevertheless does not take into account energy savings achieved from previous energy efficiency policies as from 2000 (so deadweight loss is not subtracted).
} 
(dynamic effectiveness, security of energy supply, reduction of GHG emissions, energy effectiveness, free riders, Baumol and rebound effects), (b) Efficiency (compliance costs, transaction costs, administration costs, double counting, double crediting, flexibility to exogenous price changes), (c) Innovation process (invention, innovation, and diffusion of new technologies, diffusion of existing technologies), d) Impacts on society (equity and fairness for directly affected parties, equity and fairness for indirectly affected parties, employment, environmental awareness, political acceptance and market transparency), and e) Market effects (trading and business opportunities, competition in energy markets, entry barriers, impact on energy and product prices).

Since the policy is designed for The Netherlands, we assess the scheme from a Dutch perspective. It must be noted that our assessment is purely indicative based on an estimated market function and might thus differ from what an integrated scheme would look like in actual practice. In particular, the uncertainties that we face in our ex-ante evaluation are quite large as the final scheme design and target levels are of crucial importance for the actual functioning of the scheme in practice. Table 4 presents an ex-ante assessment of our proposed scheme, comparing it with standalone policy instruments.

\section{Effectiveness}

In terms of effectiveness, an integrated $\mathrm{WhC/JI}$ scheme can be ranked highly, since a direct or indirect obligation to energy suppliers under WhC can guarantee that energy efficiency targets can be achieved. Furthermore, the provision of JI projects can stimulate further actions from the part of suppliers and market players and therefore enhance the dynamic effectiveness of the hybrid scheme. Two targets can be achieved simultaneously with no overlapping whatsoever: reduction of GHG emissions and energy efficiency. GHG emissions can be reduced due to import of ERUs, which can be used as WhC or kept as ERUs that fulfill the Kyoto Protocol targets of The Netherlands under the form of AAU's. A hybrid scheme can also assist security of energy supply in the host country since by enhancing energy efficiency in end-use sectors, peak loads can be reduced and an average relative reduction of electricity and gas demand (given a business as usual scenario) can be expected.

Depending on the design of the hybrid scheme, free riders can be discouraged since incentives for profiting through actions of other parties are not high (i.e. given a strict monitoring procedure and allowing ERUs solely from implemented energy efficiency projects). More specifically, given that suppliers have a mandatory target and cannot fulfill it but only through implementing projects or purchasing WhC, supplemented by voluntary actions on JI, Baumol effects are not expected to be high. Nevertheless, free-riding could take place if the JI projects would have been implemented anyway. This issue needs to be dealt with in the setting of baselines for the projects. Finally, as far as the rebound effect is concerned (basically a leakage factor), some studies (Binswanger 2001; Greening et al. 2000) expect an average of $20-25 \%$ reduction of the effectiveness of the energy efficiency measures. This percentage might remain stable, at least in the short term, since by importing some ERUs and converting them to WhC, suppliers can escape partly implementing 
Table 4 Evaluation of a White Certificates/Joint Implementation scheme

\begin{tabular}{|c|c|c|c|}
\hline & \multicolumn{2}{|c|}{ Baseline } & \multirow{2}{*}{$\begin{array}{l}\text { Combined } \\
\mathrm{WhC/JI}\end{array}$} \\
\hline & WhC & JI & \\
\hline \multicolumn{4}{|c|}{ Effectiveness (environmental and energy targets) } \\
\hline Reduction of GHG emissions & + & + & + \\
\hline Security of energy supply & + & $x$ & + \\
\hline Dynamic effectiveness & + & $x$ & + \\
\hline $\begin{array}{l}\text { Avoidance of negative effects (free rid- } \\
\text { ers, Baumol and rebound) } \\
\text { Cost effectiveness }\end{array}$ & - & $x$ & $x$ \\
\hline $\begin{array}{l}\text { Reduction of Compliance costs (for sup- } \\
\text { pliers, costs for complying with targets } \\
\text { set) }\end{array}$ & + & + & + \\
\hline $\begin{array}{l}\text { Reduction of Transaction costs (for sup- } \\
\text { pliers, include search, negotiating, moni- } \\
\text { toring, approval and insurance costs) }\end{array}$ & - & - & - \\
\hline $\begin{array}{l}\text { Reduction of Administrative costs (for } \\
\text { authority, costs for administrative proce- } \\
\text { dures) }\end{array}$ & - & - & - \\
\hline $\begin{array}{l}\text { Flexibility in exogenous changes (elec- } \\
\text { tricity, gas, heat and other fuel prices) }\end{array}$ & + & + & + \\
\hline \multicolumn{4}{|c|}{ Innovation process for energy efficiency technologies } \\
\hline Invention of new technologies & $x$ & $x$ & $\times$ \\
\hline Innovation of new technologies & $x$ & $\times$ & $x$ \\
\hline Diffusion of new technologies & $x$ & $\times$ & $x$ \\
\hline & \multicolumn{2}{|c|}{ Impacts on society } & + \\
\hline $\begin{array}{l}\text { Equity and fairness for direct parties } \\
\text { (suppliers) }\end{array}$ & + & + & + \\
\hline $\begin{array}{l}\text { Equity and fairness for indirect parties } \\
\text { (end users) }\end{array}$ & $?$ & $?$ & $?$ \\
\hline Employment & + & + & + \\
\hline Increase in environmental awareness & + & $x$ & + \\
\hline $\begin{array}{l}\text { Political acceptability from society } \\
\text { Market effects }\end{array}$ & $x$ & + & $\times$ \\
\hline Trading and business opportunities & + & + & + \\
\hline $\begin{array}{l}\text { Competition in energy market (market } \\
\text { liberalization, market transparency etc) }\end{array}$ & $\times$ & + & + \\
\hline $\begin{array}{l}\text { Competitiveness (prices of RE or energy } \\
\text { efficiency more competitive than fossil } \\
\text { fuel energy production) }\end{array}$ & + & $x$ & + \\
\hline
\end{tabular}

+: Refers to positive effect on criterion

-: Refers to negative effect on criterion

?: Uncertain outcome

$\times$ : Refers to neutral effect on criterion

energy efficiency projects hence consumers' behavior will not be dominated by income effect (Oikonomou et al. 2007).

\section{Efficiency}

An integrated $\mathrm{WhC} / \mathrm{JI}$ scheme can be quite efficient in terms of achieving targets set for both instruments, depending of course on the target level. More specifically, 
given the ongoing energy market conditions in The Netherlands and the cumulative experience from JI and previous energy efficiency policies, electricity and gas suppliers can reduce their overall compliance costs through opting in for voluntary actions. Parallel to the mandatory WhC obligation, which in theory can reduce costs through financing energy efficiency investments by selling WhC, suppliers can make use of cheaper options in Bulgaria. Depending on the final design of the scheme, transaction costs can be high because information acquisition and fees for external parties (independent verifiers, consultants, etc.) in addition to time costs (given that JI procedures can be time intensive) can increase these costs. Nevertheless, effects of learning curves can reduce these costs in a time scale (Michaelowa et al. 2003; UNDP 2003).

Double crediting, i.e. when two credits are generated from one single action of emissions abatement, is not expected as it can be prevented as long as monitoring mechanisms ensure that an energy efficiency action generates one ERU that is not valid anymore for any other use after being converted to WhC and they both represent the same value of energy savings. A WhC/JI scheme can furthermore adapt to price signals from exogenous market changes, namely price of oil, electricity, gas, RE and other fuels. An increase in fuel prices can be incorporated into the price of $\mathrm{WhC}$, under a cost carrying over market mechanism, and certificate market can adapt their prices according to the increased marginal cost and scarcity.

From a policy implementation perspective, a hybrid scheme based on a design as proposed in the previous sections does not incur extra administration costs since relevant and existing bodies can undertake same roles for both policies. Our estimation is based on a baseline that both policy instruments stand-alone are designed in such a way that keep administrative costs as low as possible.

\section{Innovation process}

An integrated $\mathrm{WhC/JI}$ scheme can have short and long term effects on innovation processes. The whole process consists of three steps: invention, innovation, and diffusion of new technologies. We also employ another parameter, the diffusion of existing up to date technologies. JI projects for energy efficiency are not expected to contribute substantially to new technologies, because they are based on existing technology transfer and therefore no further R\&D is stimulated. Nonetheless, JI could stimulate the transfer of state-of-the-art EU technology to new Member States or Candidate countries. Another aspect that complicates matters is that new technologies need to be verified and therefore they incur higher transaction costs and time lags before they are approved. WhC (under our proposed design) in the short term also face same bottlenecks in terms of new technologies and therefore can trigger the market of existing up to date energy efficiency products, overcoming hence technical and non-technical domestic market barriers. In the long run, however, where low-hanging fruits (no regret potentials and low cost options) will already have been exploited, innovative products and services can gain gradually market shares following the law of diminishing returns. This tendency can boost also $R \& D$ during invention and innovation phase of new technologies. In general, effects of a hybrid WhC/JI scheme on innovation can be positive but rather difficult to estimate since (local and foreign) market demand, competitiveness between technologies, existing energy saving potential, and transaction costs will determine the 
overall situation. For instance, in a study by Oikonomou et al. (2007) for The Netherlands, a domestic WhC scheme will be based on insulation and at a much lesser extent other technologies.

\section{Impacts on society}

A WhC/JI scheme under our proposed design options would have minimal negative impacts on society as a whole, but could in some cases present positive effects. More analytically, electricity and gas suppliers are treated equally and fairly, given our baseline scenario with stand alone policies. Based on welfare economics theory (e.g. Samuelson, 1947), while producer's surplus is decreased after the imposition of a direct obligation, by providing a voluntary option with lower marginal abatement costs, suppliers can minimize their original losses and finance their policy incurred costs. Depending on the degree of energy market liberalization, financing can take place through passing on increased tariffs to end users. The same principle is also valid, but at a lesser extent for indirectly affected parties, which in principle can profit from energy saving investments (either through third-party financing or direct payment) through a lower energy bill. Nevertheless, if tariffs for these investments are passed on fully to end-users societal surplus can be lowered.

Another societal criterion that can be fulfilled with the hybrid $\mathrm{WhC/JI}$ scheme is employment. Through promoting energy efficiency investments domestically and abroad, markets of energy efficiency products, ESCO's, and third parties (e.g. financial intermediaries) can be stimulated and this can lead to job creation in both countries. Furthermore, also in terms of end users, energy suppliers, and other market parties involved, energy efficiency investments with additional information campaigns can lead to an increase in environmental awareness with a subsequent change in energy consumption patterns.

Finally, the mandatory and voluntary characteristic of a hybrid scheme can trigger relatively little political opposition from directly and indirectly affected parties, than a mandatory WhC scheme alone. Depending on the design and market transparency, rules for trading can be clear for obligated parties and possibilities for profit increase can reduce political opposition.

\section{Market effects}

An integrated $\mathrm{WhC/JI}$ scheme can be rather promising in terms of market effects given the market oriented character of both policy instruments. Electricity and gas suppliers, alongside with all other market parties can make use of these mechanisms and amend their trading and business opportunities, domestically and abroad. In principle ESCO's can benefit widely from establishing trade networks of energy efficiency products and enlarge their activities in energy services. In addition to this target, a hybrid scheme can enhance competition in energy market, since energy service market will attract more participants and current oligopolistic or monopolistic threats can be diminished. This market evolution is in accordance with EU targets on liberalization of electricity and gas markets, which will also apply for Bulgaria as an accession country. Furthermore, given the energy liberalization process entry barriers for new players should be abolished. For energy efficiency products markets this should not constitute a problem, since they are liberalized at a 
great extent. Finally, an integrated $\mathrm{WhC/JI}$ scheme is not expected to increase largely energy prices, even in the case where suppliers can pass on all costs to end users. Financing domestic energy efficiency projects can take place partly through selling WhC in the market and in case of shortages, imported ERU's (generated at a low cost) can fulfill the necessary market supply, therefore obviating demand shocks and price increases. A similar effect is expected for prices of energy efficiency products that after their gradual diffusion in the market can simultaneously become competitive with conventional products.

\section{Conclusions and recommendations}

In this paper we have explored the possibilities of linking similar policy instruments (namely $\mathrm{WhC}$ and JI) in order to achieve energy efficiency improvement. WhC is a new policy instrument implemented in some EU countries. Its basic idea is that specific energy saving targets set for energy suppliers or distributors must be fulfilled by implementing energy efficiency measures towards their clients within a specific time frame. The basic idea of JI is that industrialized countries can achieve their GHG emission reduction commitments partly on the territory of other countries via emission reduction co-operation, using lower marginal abatement costs.

We attempted to identify the feasible for The Netherlands to allow a scheme where electricity and gas suppliers, under an energy efficiency obligation, can implement energy efficiency projects in buildings in another country under the form of JI. The Netherlands has been selected as country case study since it is experienced in JI projects and has already implemented many energy efficiency improvement policies. For the JI component, especially with a view to accounting procedures needed, Bulgaria is chosen as a case study country.

In The Netherlands, 33 million tonnes of $\mathrm{CO}_{2}$-equivalent emission reduction are to be achieved under JI projects as one of the tracks to reach the $6 \%$ reduction target for the country under the Kyoto Protocol. A WhC scheme for households can be cost effective and reduce up to 80 PJ primary energy in 2012, while for the period up to 2020 cumulative savings can reach a range of 180-240 PJ saved, which can be translated into 10.3-13.6 $\mathrm{Mt} \mathrm{CO}_{2}$. Therefore, an integrated JI/WhC scheme could assist substantially in achieving national (current and post-2012) targets.

A fundamental outcome is that an integrated scheme of WhC with $\mathrm{JI}$ for energy efficiency projects in the built environment can be complementary, given that the former remains a national scheme for The Netherlands. Both instruments refer to the same policy context, which facilitates a common design in terms of target setting and both can be used as certificate trading mechanisms. Furthermore, a voluntary integrated scheme of $\mathrm{JI}$ and WhC (maintaining the obligatory element of WhC) can be complementary and enhance energy efficiency improvement in a national and international level. More specifically, in terms of objectives a hybrid scheme can facilitate electricity and gas suppliers to achieve their obligations through implementing more cost-effective energy efficiency projects in another country. Nonetheless, it must be noted that given the present state of international climate negotiations there is little guidance for investors in terms of whether post-2012 reductions could be accounted, under what conditions and at what prices.

Nevertheless, two parameters must be taken into account that will determine the overall performance of the $\mathrm{WhC/JI}$ scheme: methods for defining baselines in energy 
savings and ways of converting different tradable commodities. We demonstrated differences in monitoring and verifying energy savings under both instruments and in order to reduce bottlenecks harmonized approaches for individual schemes should be maintained in an integrated WhC/JI policy. Conversion of credits from JI to WhC for tradable purposed should be allowed only if the former are proven that originate from a realized energy efficiency project and under a steady conversion rate. The success of the scheme largely depends on the fulfillment of these parameters.

Based on an ex-ante assessment, a WhC/JI scheme can be effective, since a direct or indirect obligation to energy suppliers under WhC can guarantee that energy efficiency targets can be achieved. Furthermore, it can contribute to security of energy supply in the host countries for the JI projects and provide incentives for long term spillovers, given that free riders and rebound effects are dealt with. In terms of cost-effectiveness, this scheme can achieve both reduction of GHG emissions and energy efficiency improvement at a relatively lower cost due to flexible options provided to energy suppliers. The range of costs will be determined by transaction and administrative costs, which can increase if policymakers opt in for a complicated design. Effects on innovation and diffusion of new energy efficient technologies can be positive through basically supplier's and ESCO's efforts to increase market shares under a WhC scheme. In general though, effects of a hybrid WhC/JI scheme on innovation are rather difficult to estimate since (local and foreign) market demand, competitiveness between technologies, existing energy saving potential, and transaction costs will determine the overall situation. A WhC/JI scheme under our proposed design options can have minimal negative (or almost neutral) impacts on society as a whole while in some cases some positive effects can be present, namely in terms of employment and increase in environmental awareness. Finally, such a scheme can be rather promising in terms of market effects given the market oriented character of both policy instruments, since it can be compatible with energy market liberalization and increase competitiveness of specific "cleaner" technologies.

Nonetheless, despite the positive outcome of the feasibility assessment of the hybrid scheme, it is noted that contrary to the even mixing of GHG in the atmosphere, which makes the location of GHG abatement measures irrelevant for their effectiveness, energy efficiency measures have mainly an effect on the site where they are carried out. This implies that energy efficiency measures carried out abroad and translated into WhC for use in The Netherlands replace energy efficiency improvements in The Netherlands that would have been carried with domestic action only. This issue requires a political consideration and could lead to a full conversion of JI credits into WhC (as assumed in this paper) or a limited/discounted where energy efficiency JI projects are only partially credited as WhC, so that still some further energy efficiency investments within The Netherlands would be needed to comply with WhC commitments. This paper has shown the fundamentals of a hybrid system, so that such political considerations have been left out for now.

\section{References}

Begg K, Jepma CJ, Sorrell S, WP, v. d. G. (2002) Guidance for UK Emissions Trading Projects. Advise to the UK Government (DTI), carried out by the University of Surrey and the University of Sussex, UK, and Foundation JIN, The Netherlands 
Bertoldi P, Rezessy S (2006) Tradable certificates for energy savings (White Certificates). European Commission Joint Research Centre

Bertoldi P, Rezessy S, Langniss O, Voogt M (2005) White, Green and Brown certificates: how to make the most of them? European Commission Joint Research Centre

Binswanger M (2001) Technological progress and sustainable development: what about the rebound effect? Ecological Economics 36(1):119-132

Boonekamp PGM (2006) Evaluation of methods used to determine realized energy savings. Energy Policy 34(18):3977-3992

Bossi M, Ellis J (2005) Exploring options for 'Sectoral Crediting Mechanisms'. OECD/IEA, Paris, France

CE (2005) Interim evaluation of the Dutch Joint Implementation Programme, executive summary. Delft, The Netherlands

EC (2002) Directive 2002/91/EC of the European Parliament and of the Council on the energy performance of buildings. Official Journal of the European Communities 4.1.2003

EC (2004) Directive 2004/101/EC of the European Parliament and of the Council amending Directive 2003/87/EC establishing a scheme for greenhouse gas emission allowance trading within the Community, in respect of the Kyoto Protocol's project mechanisms. Official Journal of the European Union 13.11.2004

EC (2006a) Directive 2006/32/EC of the European Parliament and of the Council on energy end-use efficiency and energy services and repealing Council Directive 93/76/EEC. Official Journal of the European Union 27.4.2006

EC (2006b) Action Plan for Energy Efficiency: Realising the Potential, COM (2006) 545 final, Brussels

Farinelli U, Johansson T, McCormick K, Mundaca L, Oikonomou V, Örtenvik M, Patel M, Santi F (2005) "White and Green": Comparison of market-based instruments to promote energy efficiency. J Cleaner Production 13(10-11):1015-1026

Goldewijk KK, Olivier JGJ, Peters JAHW, Coenen PWHG, Vreuls HHJ (2005) Greenhouse gas emissions in The Netherlands1990-2003 national inventory report 2005. RIVM/MNP, Bilthoven, The Netherlands

Greening LA, Greene DL, Difiglio C (2000) Energy efficiency and consumption-the rebound effect-a survey. Energy Policy 28(6-7):389-401

Guardiola M, Naturel B, Perret L, Renaudie G (2004) Les Certificats d'Economie d'energie. Rapport pour l'atelier changement climatique, Ecole Nationale des Ponts et Chausses, France

International Energy Agency (2003) Energy balances of OECD countries 2000-2001. OECD/IEA, Paris CEDEX, France

International Energy Agency (2006) Market Mechanisms for White Certificates Trading-Task XIV Final Report. Capozza A (ed) Implementing Agreement on Demand-Side Management Technologies and Programmes. CESI Ricerca, Milano, Italy

Joosen S, Harmelink M, Blok K (2004) Evaluatie van het klimaatbeleid in de gebouwde omgeving 1995-2002. ECOFYS, Utrecht, The Netherlands

Michaelowa A, Stronzik M, Eckermann F, Hunt A (2003) Transaction costs of the Kyoto Mechanisms. Climate Policy 3(3):261-278

MinEZ (2005) Now for later-energy report. Ministry of Economic Affairs, the Hague, The Netherlands

Mundaca L, Santi F (2004) Quantitative assessment of selected policy instruments using the Western European MARKAL model, Phase III of the EU SAVE "White and Green" project. International Institute for Industrial Environmental Economics, University of Lund, Sweden

Oikonomou V (2004) A qualitative analysis of White, Green Certificates and $\mathrm{EU} \mathrm{CO}_{2}$ allowances, Phase II of the EU SAVE "White and Green" project. Copernicus Institute, Utrecht University, The Netherlands

Oikonomou V, Jepma CJ (2006) A qualitative methodology on analyzing climate change and energy policy instruments. University of Groningen, Energy Delta Research Centre (EDReC), Groningen, The Netherlands

Oikonomou V, Rietbergen M, Patel M (2007) An ex-ante evaluation of a White Certificates scheme in The Netherlands: A case study for the household sector. Energy Policy 35(2):1147-1163

Poel B (2005) Measuring energy savings in buildings. In: Energy Convention conference, Groningen, The Netherlands, 27-28 November 2005

Samuelson PA (1947, Enlarged ed. 1983). Welfare Economics, Foundations of Economic Analysis. Harvard University Press, Cambridge, MA, ch. VIII, pp 203-53 
Schneider H (2005) Tradable Energy Saving Certificates (ESC) in The Netherlands - considerations \& possible design. In: Energy Convention conference, Groningen, The Netherlands, 27-28 November 2005

Schneider H, Burgers J, Ducos V (2005) Tradable energy saving certificates: added value and feasibility. CEA, Delft, The Netherlands

UNDP (2003) The clean development mechanism: a user's guide. Bureau for Development Policy. Energy \& Environment Group, New York

Van der Gaast W (2002) The scope for Joint Implementation in the EU candidate countries. Int Environ Agreements: Politics, Law Economics 2(3):275-290

Van der Gaast W (2005) Baseline standardisation in JI Track-I and Green Investment Schemes. In: JI Track-I workshop, Prague, Czech Republic 